\title{
Facilitators and barriers to the regulation of medical cannabis: a scoping review of the peer-reviewed literature
}

\author{
Mohammad Ali Ruheel ${ }^{\dagger}$, Zoya Gomes ${ }^{\dagger}$, Sana Usman, Pargol Homayouni and Jeremy Y. Ng ${ }^{*}$ (i)
}

\begin{abstract}
Background: In recent decades, several political, legislative, judicial, consumer, and commercial processes around the world have advanced legalization efforts for the use of medical cannabis (MC). As the use of MC evolves through legislative reform, with an increase in public acceptance and therapeutic potential, a need exists to further investigate the facilitators and barriers to $M C$ regulation.

Methods: A scoping review was conducted to identify the facilitators and barriers associated with the implementation of MC regulations. MEDLINE, EMBASE, AMED and PsycINFO databases were systematically searched; no restrictions were placed on geographic location/jurisdiction. Eligible articles included those that evaluated the MC regulatory framework of one or more countries.

Results: Twenty-two articles were deemed eligible and included in this review. Themes identified include: (1) effects of conflicts, mindset, and ideology of state population, (2) the use of comparisons to analyze MC regulation, and (3) the need for more knowledge, advice, and empirical/clinical evidence to inform future MC policies.

Conclusion: Policymakers should be aware of facilitators to the MC regulation implementation process, such as the influence of state and federal congruence, increased transparency, and the incorporation of stakeholder concerns, in order to effectively respond to a growing societal acceptance of $M C$ and its use among patients. Given a comprehensive understanding of these influential factors, policymakers may be better equipped to meet the consumer and commercial demands of a rapidly evolving $\mathrm{MC}$ regulatory environment.
\end{abstract}

Keywords: Medical cannabis, Medical marijuana, Scoping review, Regulation, Policy

\section{Background}

The use of medical cannabis (MC) dates back thousands of years, first appearing in a medical text composed by Emperor Shen-Nung around 2800 BCE documenting its potential in treating various conditions [1]. By the

\footnotetext{
*Correspondence: ngjy2@mcmaster.ca

${ }^{\dagger}$ Mohammad Ali Ruheel and Zoya Gomes have contributed equally contributed to this work

Department of Health Research Methods, Evidence, and Impact, Faculty of Health Sciences, McMaster University, Michael G. DeGroote Centre for Learning and Discovery, Room 2112, 1280 Main Street West, Hamilton, ON L8S 4K1, Canada
}

nineteenth century, an increase in the recreational use of cannabis prompted the emergence of various prohibition laws and policies due to controversies surrounding its legal, ethical, and societal implications [2]. Opponents of MC legalization in the twentieth and twenty-first centuries cited its addictive properties, associations with criminal behaviours, and a lack of medical evidence as drivers for its sustained illegality [3]. In the 1950s and 1960s, however, the budding popularization of recreational cannabis also propelled scientific investigation into its therapeutic capacities [1]. In recent decades, several political, legislative, judicial, consumer, and commercial processes around the world have advanced legalization original author(s) and the source, provide a link to the Creative Commons licence, and indicate if changes were made. The images or other third party material in this article are included in the article's Creative Commons licence, unless indicated otherwise in a credit line to the material. If material is not included in the article's Creative Commons licence and your intended use is not permitted by statutory regulation or exceeds the permitted use, you will need to obtain permission directly from the copyright holder. To view a copy of this licence, visit http://creativecommons.org/licenses/by/4.0/. The Creative Commons Public Domain Dedication waiver (http://creativeco mmons.org/publicdomain/zero/1.0/) applies to the data made available in this article, unless otherwise stated in a credit line to the data. 
efforts for the use of MC [1, 4]. In 1999, Canada became one of the first nations to initiate a centralized MC program and provide $\mathrm{MC}$ prescriptions to patients [1,5]. Similarly, in 1996, California became the first US state to legalize MC and by 2016, this transition had been consolidated across the majority of the US [4]. There is also a continuous pressure for the implementation of MC laws beyond North American jurisdictions. In 2019, Thailand amended its original law, the Narcotic Act B.E. 2522, shifting from the strict prohibition of cannabis to legalizing its medical use under certain conditions [6]. Further, in 2013, Uruguay became the first country to legalize cannabis through government public health efforts, while in countries such as Argentina, Brazil and Mexico, legislative reforms have not adapted to achieve the same extent of regulation [7]. As of today, MC programs have been established in various countries around the world, including but not limited to Canada, Colombia, Chile, Germany, Israel, Italy, Jamaica, the Netherlands, Switzerland, Thailand, the United Kingdom (UK), Uruguay, and more than 30 US states [6].

While some researchers continue to express concern over cannabis use including possible adverse outcomes, potential for dependence, and associated national stigma, the usage of $\mathrm{MC}$ continues to rise [2]. It is estimated that over 3.5 million Americans used MC legally in 2019 and Canadian MC prescriptions tripled from 30537 in 2015 to 100000 in 2016 [5]. Additionally, the Netherlands has seen a dramatic increase in patients using MC since its legalization in 2000, with over 50000 patients now being prescribed MC [7]. Other countries including Greece, Poland, and Slovenia are following closely behind and have adopted various MC regulation schemes [7]. Furthermore, in 2017, due to the growing popularity of MC, New Zealand introduced the Misuse of Drugs Amendment Bill with the objective of making MC accessible to citizens without criminal liability [7].

Although a reasonable degree of clinical ambiguity surrounding the benefits and challenges of MC continues to exist, ongoing research has shown promise for the use of $\mathrm{MC}$ in treating various medical conditions [5]. Several randomized controlled trials have assessed the effects of MC on fibromyalgia, epilepsy, traumatic brain injury, neurological disorders, and a considerable number of other conditions and symptoms [5]. Current literature outlines that there exists substantial evidence for the efficacy of $\mathrm{MC}$ in treating conditions including chronic pain and multiple sclerosis-related spasticity, with conclusive or limited evidence for symptoms such as cancer-related nausea [5]. As MC prohibition continues to be lifted through legislative action, certain populations have demonstrated an increasing acceptance of MC usage. In 2016, a Quinnipiac University poll found that 81 percent of
American respondents were in favor of $\mathrm{MC}$ legalization [2]. In addition, citizens of Israel and Norway have shown an increase in public support for MC legalization due to increasing beliefs about the potential medical effects of cannabis [8].

There has been significant controversy surrounding the implementation of centralized national medical cannabis programs in countries including Canada, the US, and the Netherlands, with criticism from judicial courts, medical establishments, law enforcement and consumers themselves [1]. Further regulation of $\mathrm{MC}$ will depend on the expansion of clinical research programs, government cooperation, and community-based strategies in order to promote safe and equitable access [1]. Without a clear understanding of its regulatory history, conflicting evidence and unrelenting media attention can present MC policy formulation and implementation as an incredibly difficult task [9].

To our knowledge, there is no current literature that summarizes the facilitators and barriers to $\mathrm{MC}$ regulation, which takes into account no restriction on country or jurisdiction. Given that there is a growing body of evidence to suggest that $\mathrm{MC}$ use is evolving through legislative actions, with an increase in public acceptance and therapeutic potential, there is a need for further investigation into the factors that affect MC policy formulation. As such, the objective of this scoping review is to identify and summarize the facilitators and barriers to $\mathrm{MC}$ regulation throughout different parts of the world.

\section{Methods \\ Approach}

A scoping review was conducted to identify the facilitators and barriers to the regulation of MC; the scoping review was informed by Arksey and O'Malley's [10] framework, and further supplemented by Levac et al. [11] and Daudt et al. [12]. The methodology consists of fivestages, as follows: (1) identifying the research question; (2) identifying relevant studies; (3) selecting the studies; (4) charting the data, and (5) collating, summarizing, and reporting the results $[10,11]$. We chose this method as it provided an outline for searching and evaluating current literature on the present topic, determining eligibility criteria, and summarizing eligible article content to identify themes and highlight knowledge gaps. Our registered study protocol on Open Science Framework can be found at: https://doi.org/10.17605/OSF.IO/6HGRX.

\section{Step 1: identifying the research question}

The research question for this scoping review was as follows: "What facilitators and barriers to the regulation of $\mathrm{MC}$ can be identified by studies evaluating policies and regulatory frameworks across different countries?". For 
this study, we defined a "facilitator" as any factor(s) that allow(s) or promote(s) the implementation of $\mathrm{MC}$ regulation. An example of a facilitator to $\mathrm{MC}$ regulation can include the congruence of federal and state laws regarding $\mathrm{MC}$ usage. On the other hand, we defined a "barrier" as any factor(s) that prevent(s) or hinder(s) the implementation of $\mathrm{MC}$ regulation. Some general examples of barriers to $\mathrm{MC}$ regulation can include $\mathrm{MC}$ stigma, negative public mindset, or a lack of knowledge surrounding $\mathrm{MC}$ usage and benefits.

\section{Step 2: identifying relevant studies}

Following a preliminary scan of the literature, we conducted systematic searches on June 01, 2020 from database inception until May 29, 2020 on MEDLINE, EMBASE, AMED, and PsycINFO. The search strategy included indexed headings and terms used in the literature to refer to $\mathrm{MC}$ regulation. A sample search strategy can be found in Table 1 . We elected not to search the grey literature, as we specifically wanted to identify facilitators and barriers identified by policy evaluations, which are academic studies likely to be published only in the peerreviewed literature.

\section{Step 3: selecting the studies}

Our preliminary scans of the academic literature allowed us to identify some eligible articles. We included all primary research articles, research protocols, and review articles that evaluated MC regulations in one or more countries globally. In this case, we define a "review" as an article that has examined barriers and/or facilitators to the implementation of MC policy formulation or regulation, and also included those that were not systematic or scoping reviews. The reference lists of ineligible review articles were read to source additional articles that could potentially meet our eligibility criteria. Exclusion criteria included content outside of MC or articles which solely focused on the recreational use of cannabis. Articles in the form of commentaries, editorials, letters to the editor, conference abstracts, and opinion pieces were also ineligible. Further, our eligibility criteria restricted our search to articles published solely in the English language and those publicly accessible or retrievable through a library system. SU and PH independently pilotscreened all retrieved articles to first determine eligibility based on title and abstract. A second round of screening was then conducted to determine eligible articles based on their full text. Each round of independent screening was followed by a discussion between JYN, SU, and PH to reach a consensus on which articles were considered eligible and to determine any inconsistencies or questions regarding the inclusion criteria. Discrepancies were resolved by discussion.

\section{Step 4: charting the data}

We developed a data extraction form that allowed us to evaluate each article and to identify any relevant information. The following data from each eligible article was summarized and extracted: author(s); year of publication; study design; country/countries discussed; the objective of the study; participants/level of policy-making; types of evidence from which the evaluation of the $\mathrm{MC}$ regulation was made; summary of methods; facilitators to the implementation of $\mathrm{MC}$ regulations; and barriers to the implementation of $\mathrm{MC}$ regulations. Following data extraction being conducted independently and in duplicate, JYN, $\mathrm{SU}$, and $\mathrm{PH}$ met to discuss and resolve discrepancies. The aim of the data extraction was to collect and analyze information from included studies required to identify relevant themes and subthemes.

Table 1 OVID search strategy executed June 01, 2020

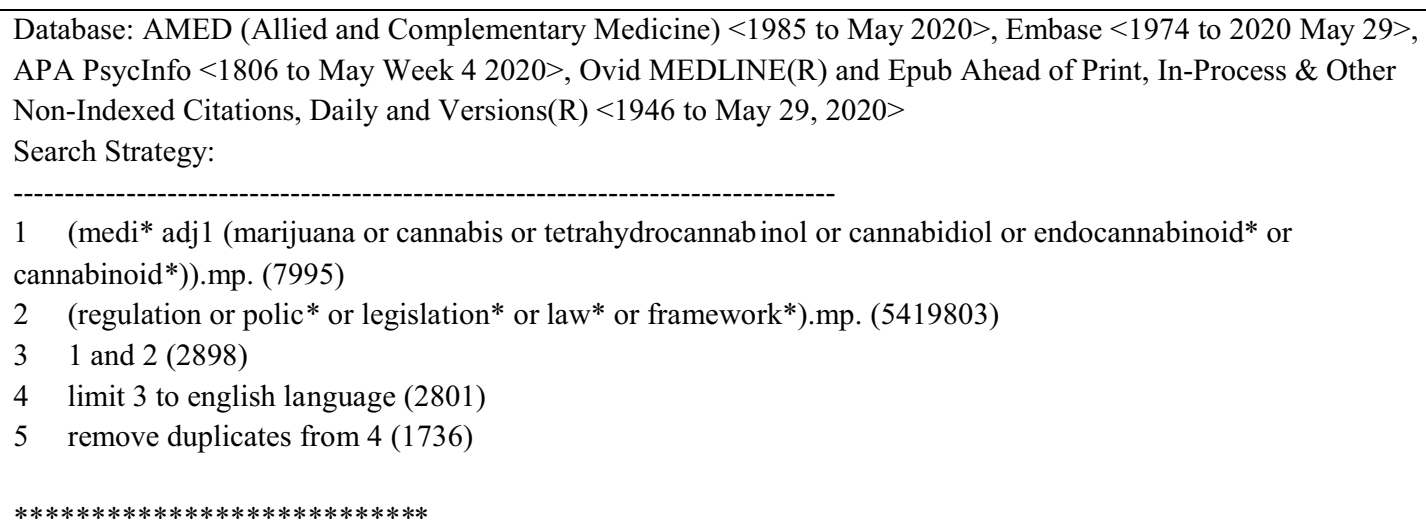


Step 5: collating, summarizing, and reporting the results Charted data was summarized in the format of tables, and the descriptive data was analyzed using content analysis. MAR, ZG, and JYN reviewed the descriptive data and resolved any discrepancies through discussion. JYN identified codes relative to the findings, and all authors subsequently organized the findings into themes.

\section{Results}

Searches generated a total of 2801 results, 1065 of which were duplicates; following title/abstract screening, 1695 items were excluded, leaving 41 full-texts to be assessed. After full-text screening, 19 items failed to meet the eligibility criteria because they did not evaluate the facilitators and/or barriers to $\mathrm{MC}$ regulation $(n=17)$, were a conference abstract $(n=1)$, or were irretrievable $(n=1)$, resulting in a total of 22 eligible articles that were included in this scoping review. A PRISMA diagram detailing this process is shown in Fig. 1.

\section{Eligible article characteristics}

Eligible articles were published between 2002 and 2019 inclusive, and originated from the US $(n=16)$, Canada $(n=2)$, Israel $(n=2)$, Japan $(n=1)$, and the UK $(n=1)$. The countries discussed included the US $(n=16)$, Canada $(n=3)$, Israel $(n=2)$, Germany $(n=1)$, Jamaica $(n=1)$, Japan $(n=1)$, UK $(n=1)$, and Uruguay $(n=1)$. The 22 eligible articles had varying study designs and some studies employed multiple designs; while the majority of articles were policy analyses $(n=14)$, there were also interviews $(n=5)$, literature reviews $(n=4)$, surveys $(n=4)$, case studies $(n=3)$, and a comparative analysis $(n=1)$. Specifically, the comparative analysis examined laws, regulations, and discussions with regulators and functionaries of each jurisdiction. Many of the policy analyses touched upon medical marijuana laws (MMLs) specific to each country on a federal or state level while drawing upon key information from interviews with stakeholders in the MC policy field. Additionally, interviews and/or surveys were common methods used to gather evidence to evaluate $\mathrm{MC}$ programs. The case studies analyzed regulatory acts, political structures, and archival advisory material. Further details associated with all eligible articles referenced in this review, including study objectives and study design can be found in Table 2. A summary of study methods, types of evidence, and facilitators and barriers to $\mathrm{MC}$ regulation across eligible articles can be found in Table 3.

\section{Finding from thematic analysis}

The data extracted from this search was organized into the following themes, which included: (1) the effects of conflicts, mindset, and ideology of the state population, (2) the use of comparisons to analyze MC regulations, and (3) the need for more knowledge, advice, and empirical evidence to inform future $\mathrm{MC}$ policies.

\section{Effects of conflicts, mindset, and ideology of the state population}

Upon reviewing the 22 eligible articles, we found that 10 discussed the impact of conflict and/or population mindset on the implementation of MC regulation.

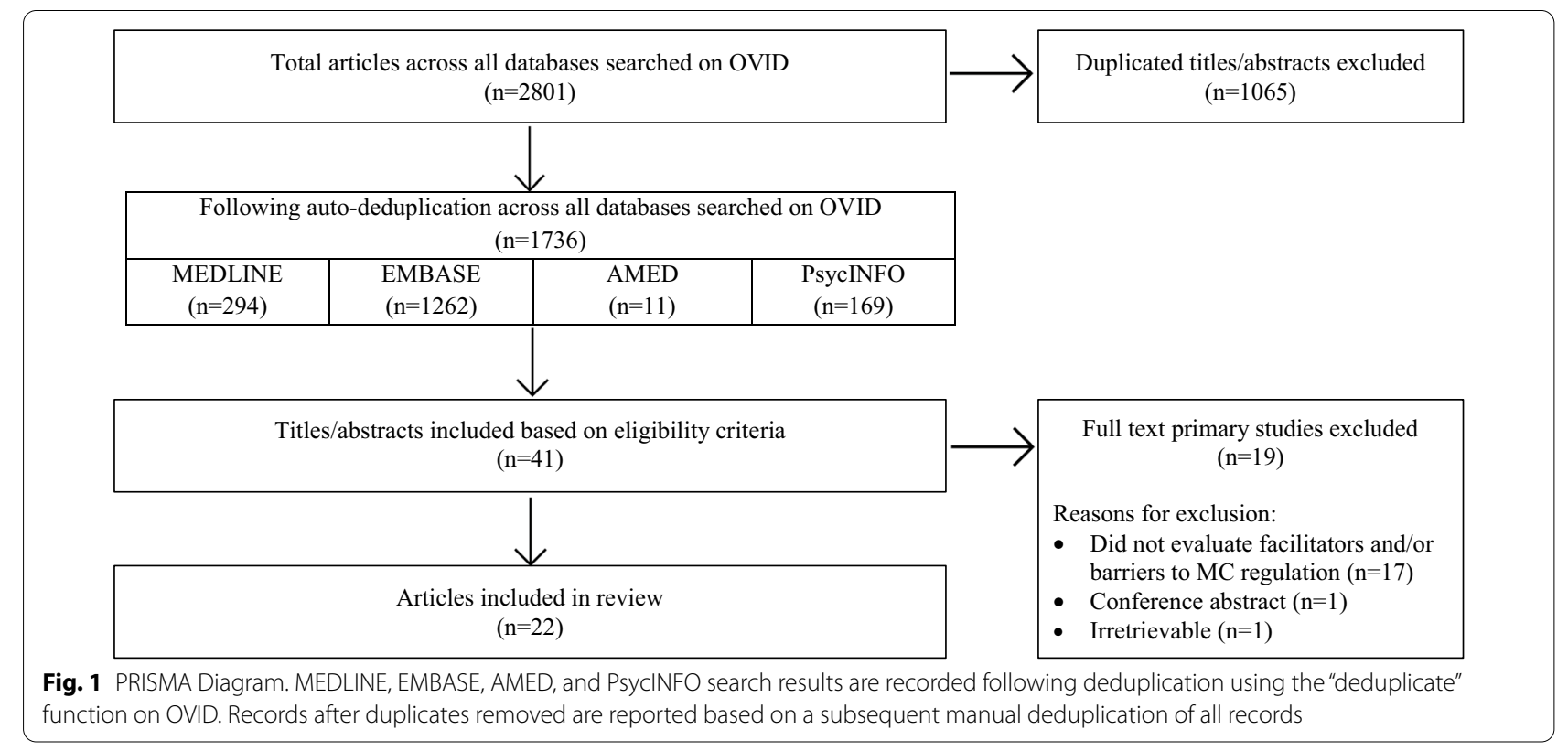




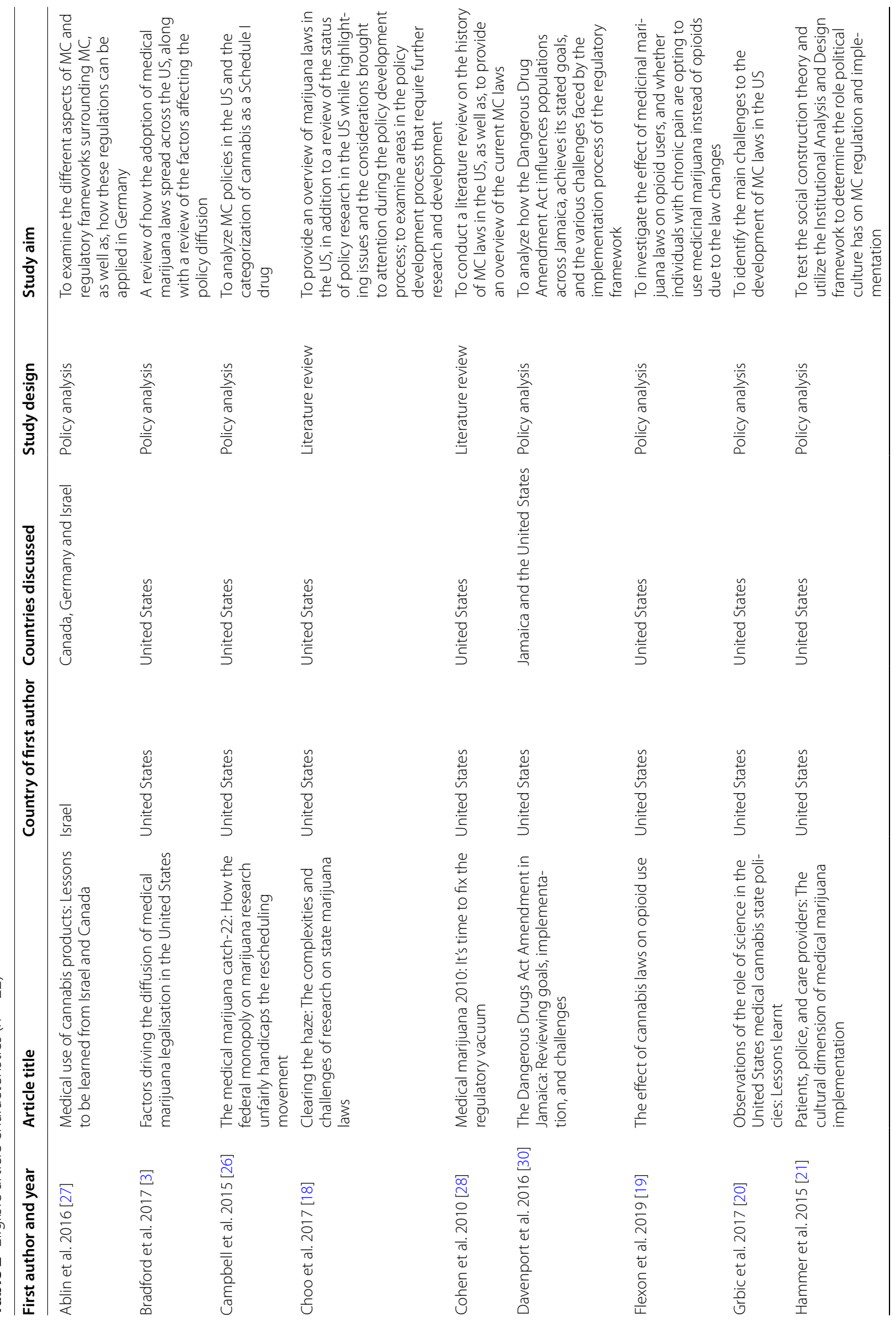




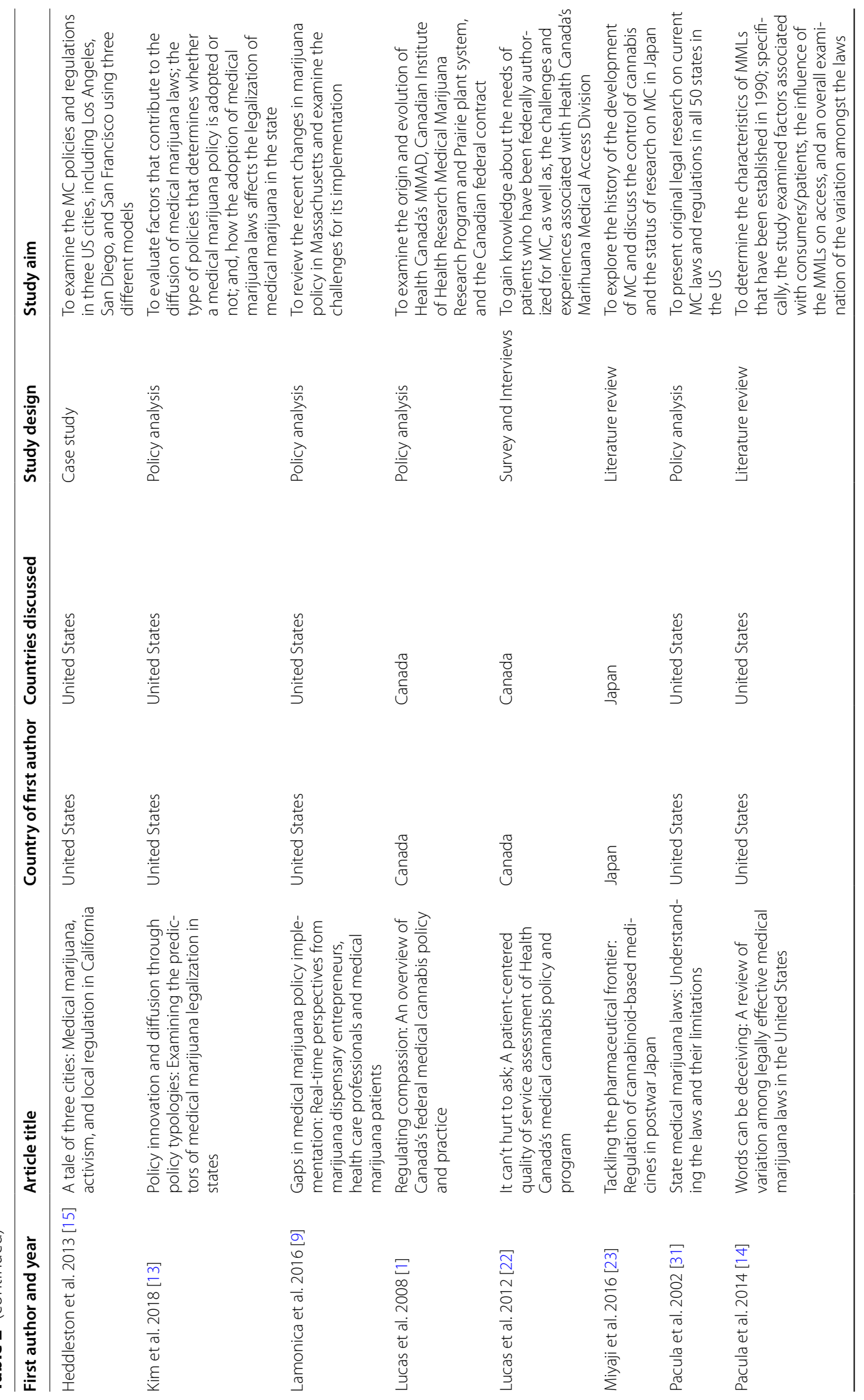




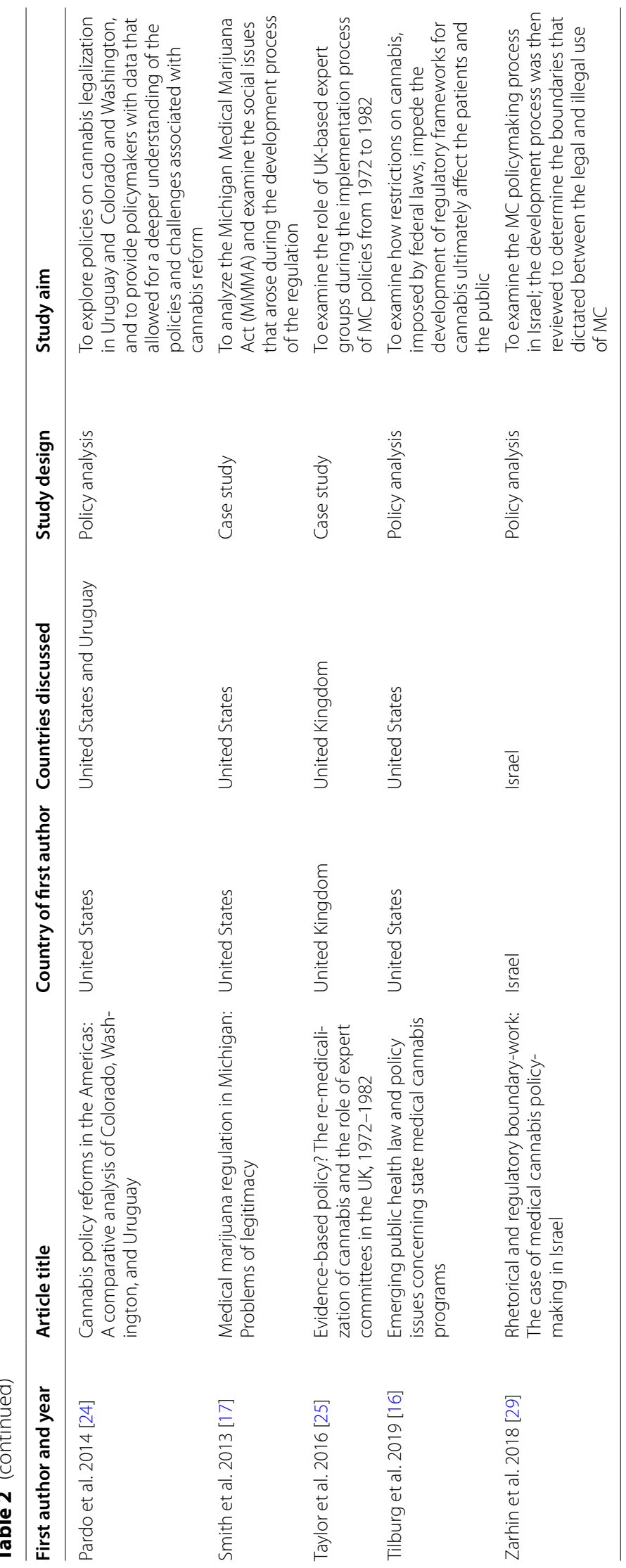




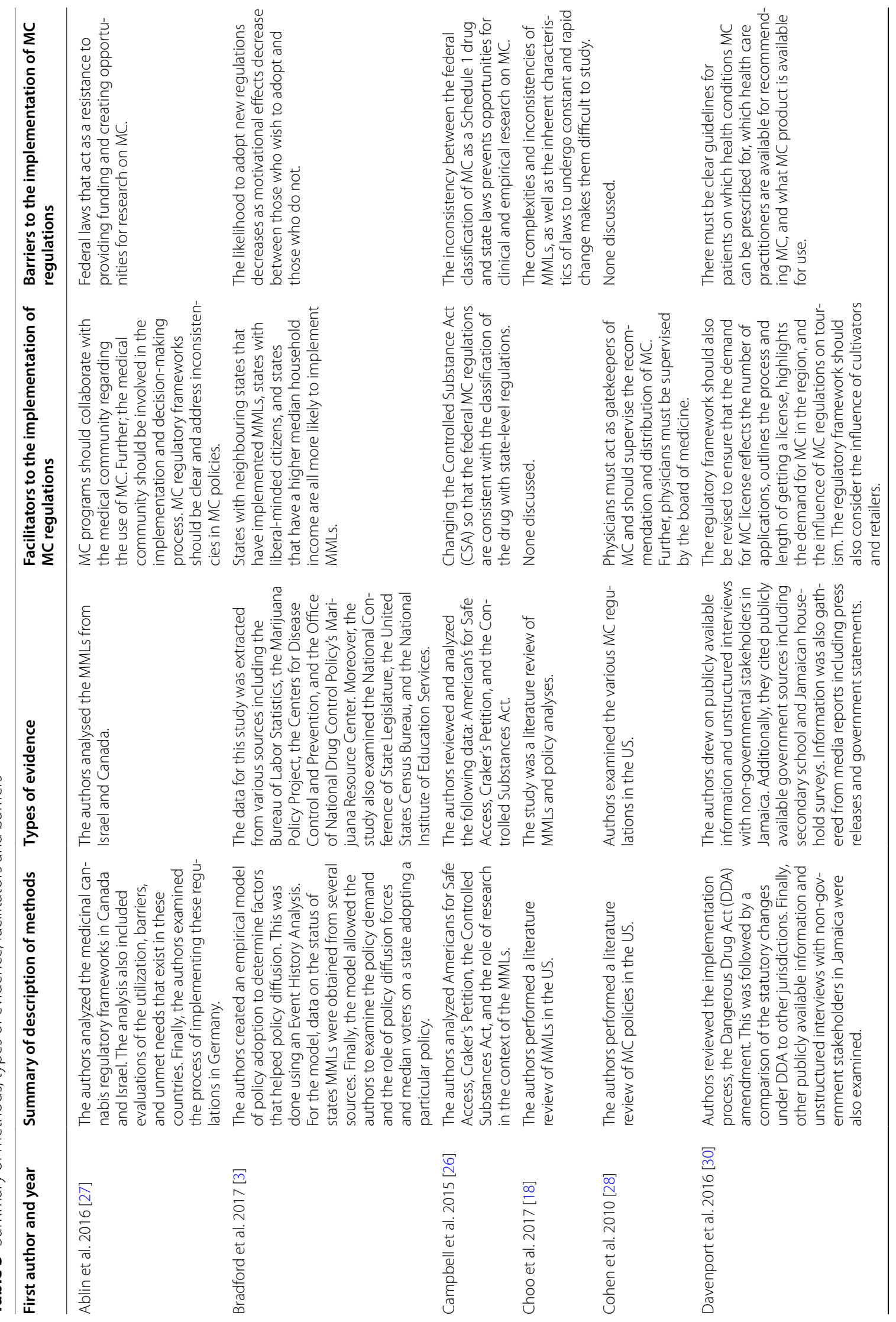




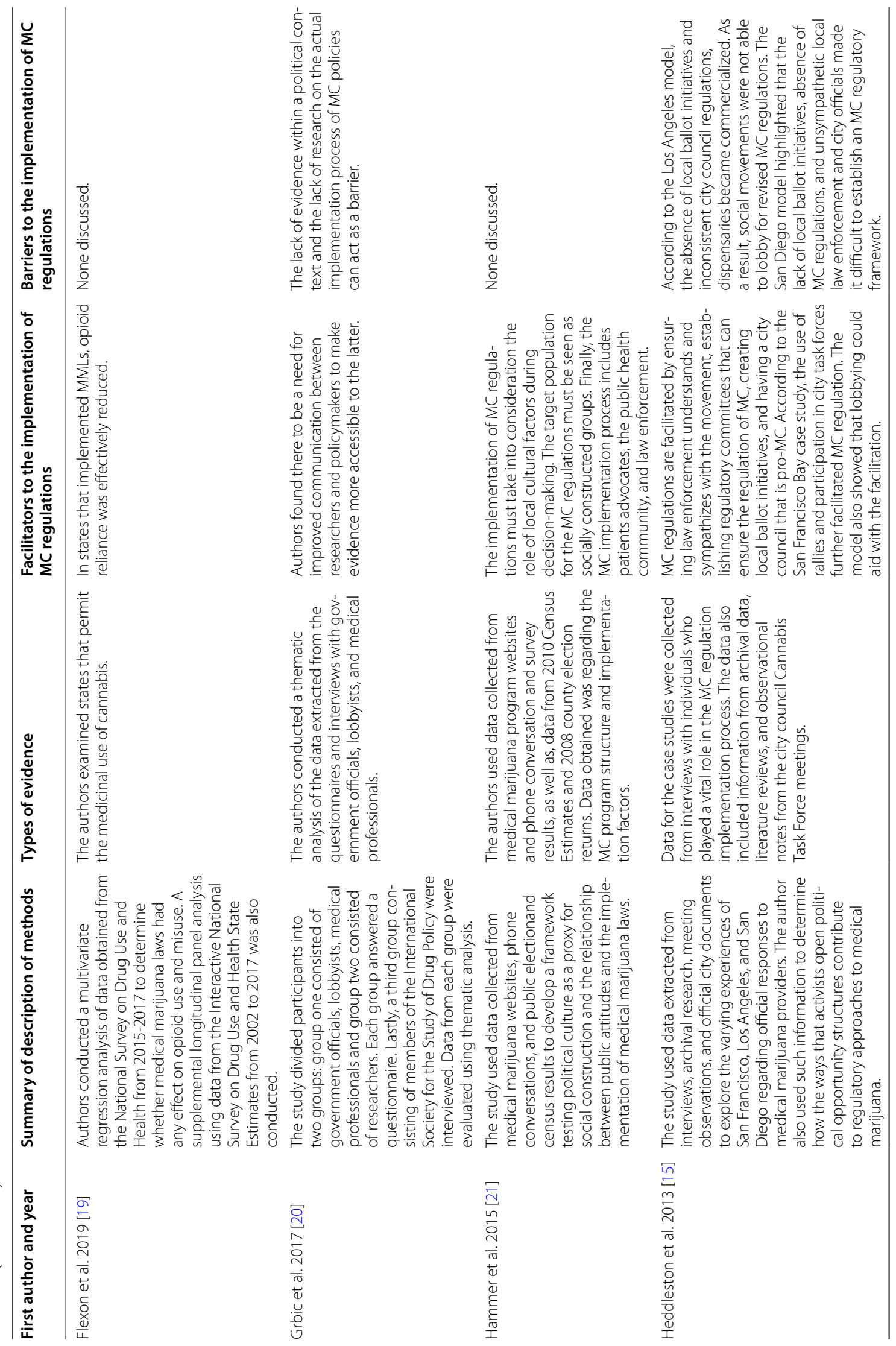




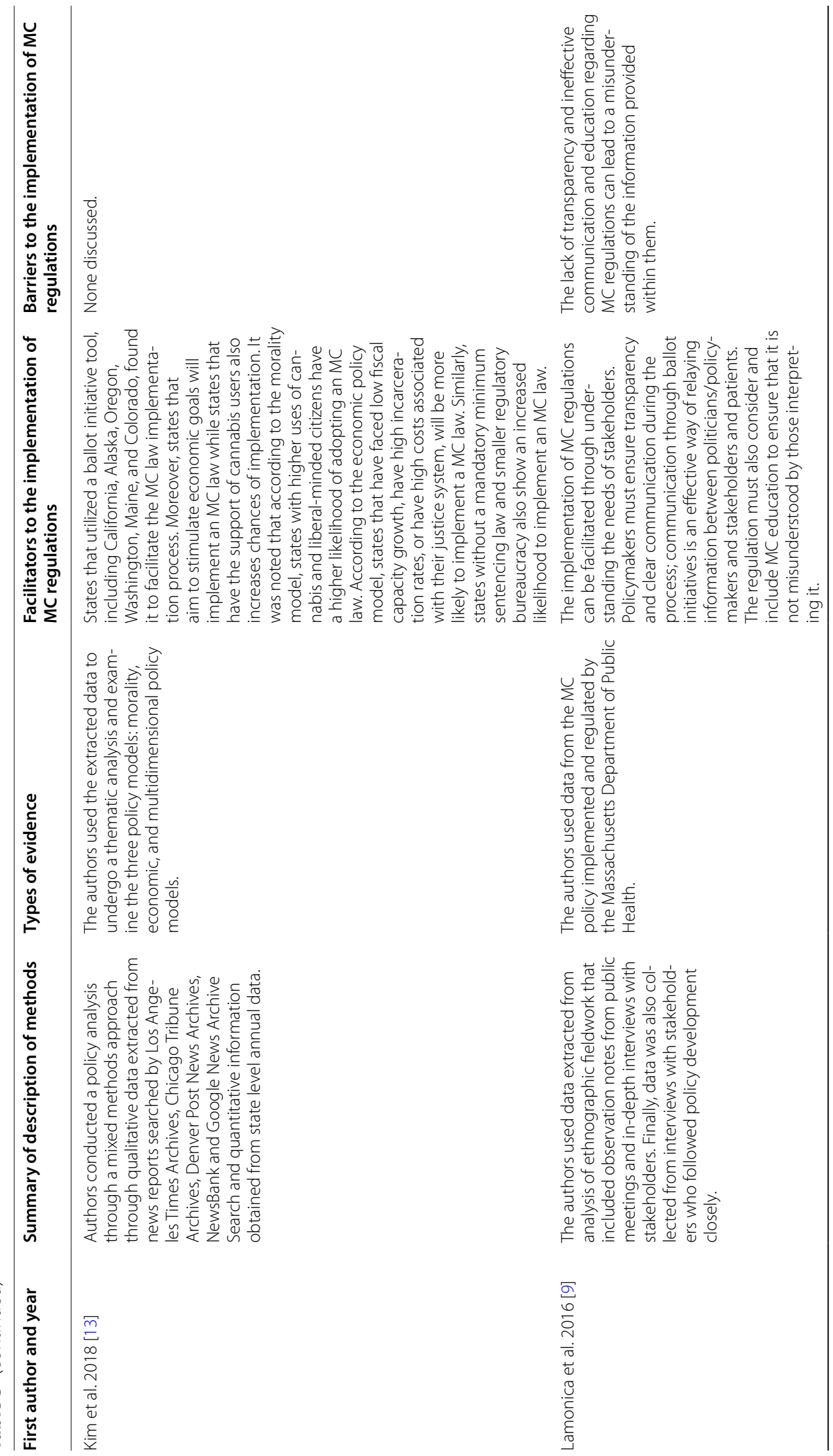




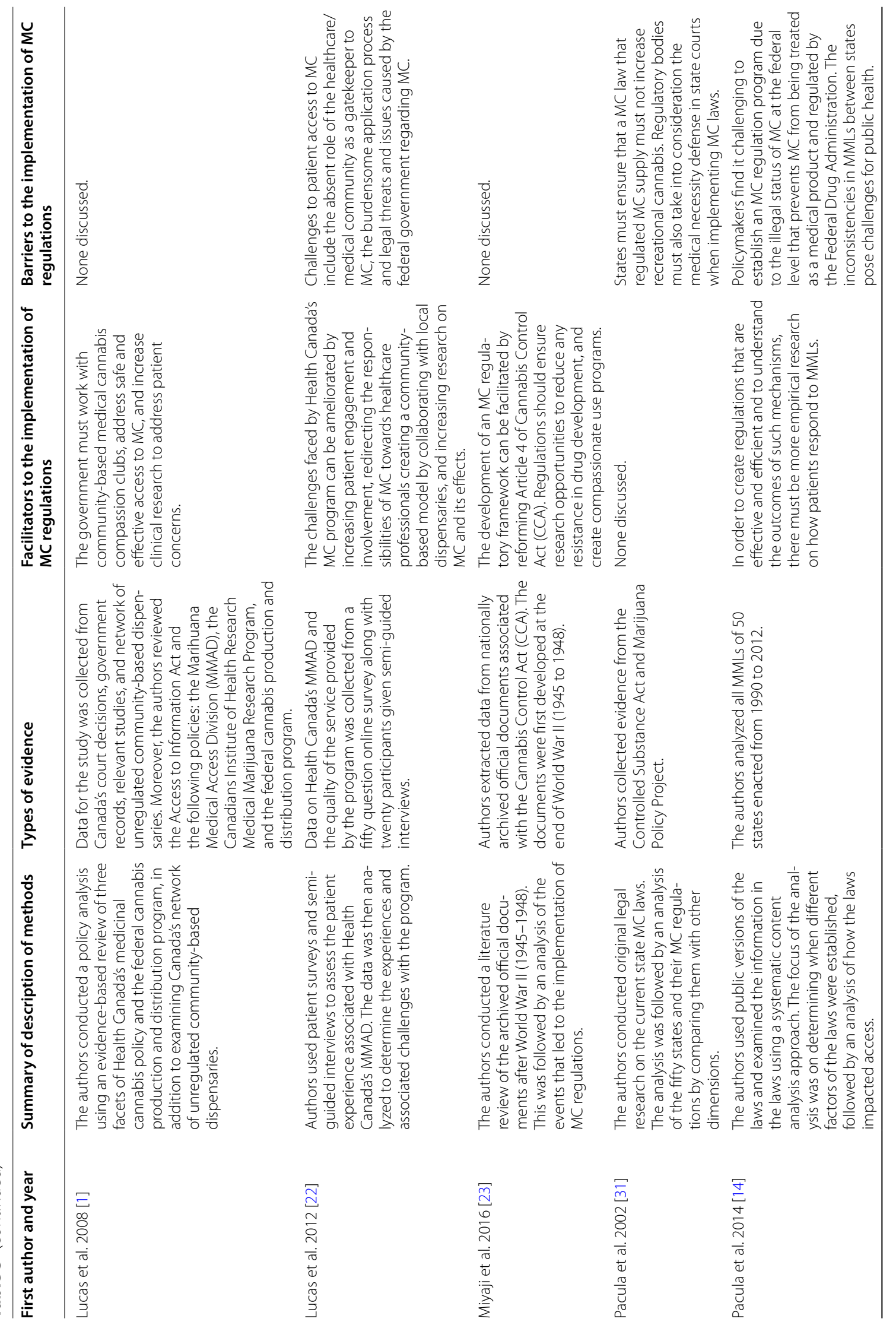




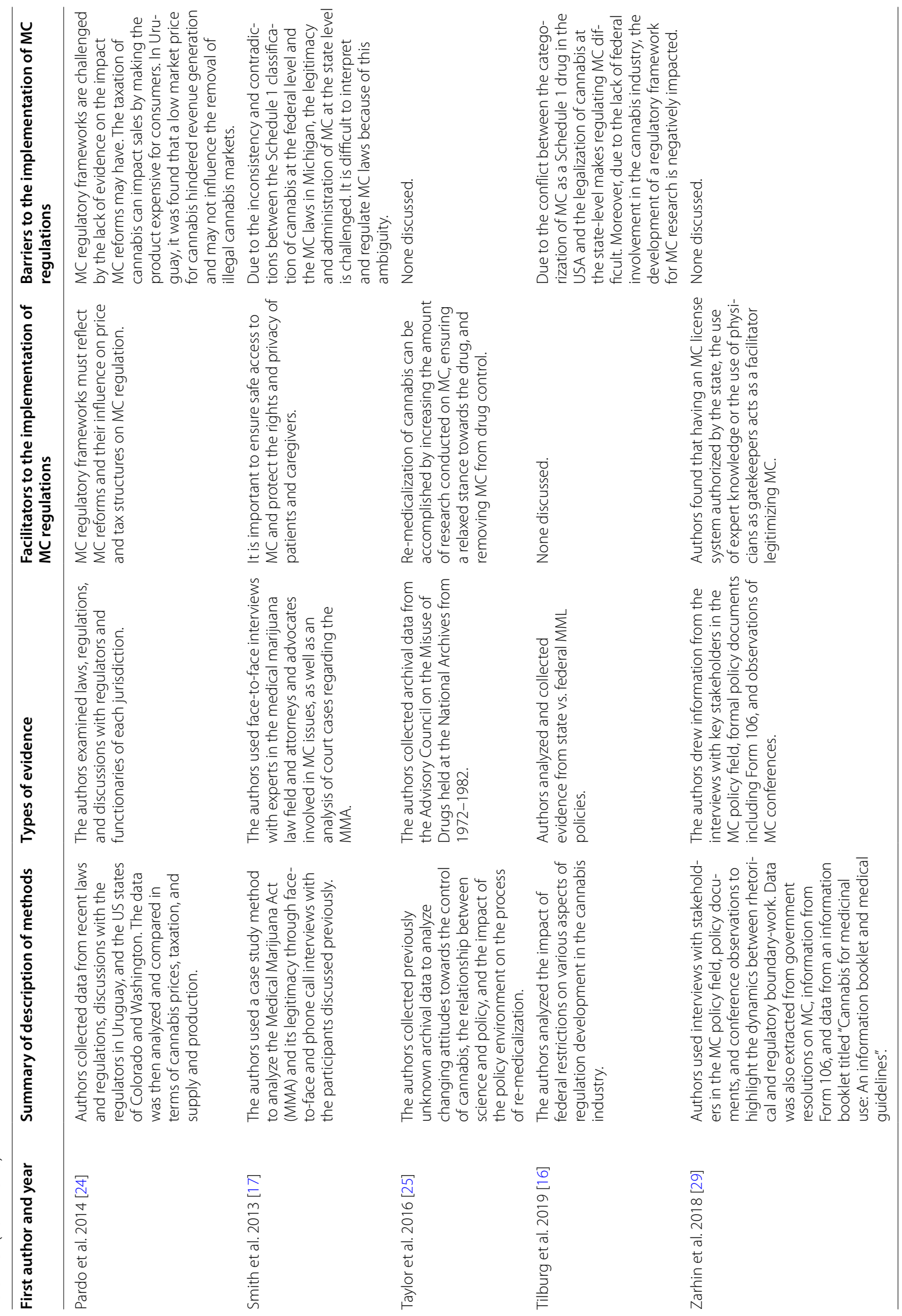


Citizen-specific characteristics such as liberal-belief systems $[3,13]$ and higher cannabis use [13] were found to encourage MC law instatement while widespread faith in Christianity was a barrier [14]. State-specific factors such as neighbouring $\mathrm{MC}$ laws could act as facilitators or barriers as the adoption of a policy was more likely if it existed in a neighboring state [3], while ballot initiative measures often facilitated MC laws. More specifically, ballot measures provided opportunities for stakeholders, politicians, and policymakers to address the needs of citizens in their political work, acting as a facilitator for MC regulation $[9,13,15]$. We also found conflicts between state and federal scheduling of MC regulation to be a barrier and a source of regulation heterogeneity. Incongruence between federal and state governments made it more difficult to create a $\mathrm{MC}$ regulation system $[14,16]$, questioned administrative legitimacy and threatened MC laws [17], and infringed upon $\mathrm{MC}$ clinical research [15, $16,18]$. A unique conclusion drawn from one study was that MML implementation reduced opioid overreliance, potentially prompting states to view future $\mathrm{MC}$ regulation through a positive lense [19]. In demonstrating that state mindset can act as a barrier or facilitator, it is evident that successful MC regulation calls upon greater transparency, a better understanding of stakeholder concerns, and a more effective method of communicating regulation and political implications $[9,20]$.

\section{Use of comparisons to analyze $M C$ regulation}

We found that a commonly used method for evaluating $\mathrm{MC}$ regulation was through the use of comparisons. More specifically, authors conveyed research comparing cannabis dispensaries, different US state MC laws, and individual country MC laws.

Cannabis dispensaries were used to study MC policy development through in-depth interviews with MC dispensary entrepreneurs [9], critical evaluations of unregulated community dispensaries [1], and structural examinations of dispensaries [21]. Cannabis dispensaries were also frequently cited as potential facilitators if successfully incorporated into community-based models of $\mathrm{MC}$ regulation or compassionate use programs $[1,22$, 23].

Researchers reviewed how the adoption of MMLs spread across US states affected policy diffusion $[3,13]$. A comparison across states in multiple articles reiterated the influence of neighboring states in the adoption process $[3,13]$. Individual states faced barriers in creating an MC regulation system as it requires federal approval [14]. Comparisons between countries allowed for $\mathrm{MC}$ regulation to be conceptualized in different jurisdictions. This contributed to an understanding of barriers to MC policy implementation including the need to consider commercialization and empirical evidence on the effects of MC reforms [24]. Analyses comparing MC laws in major cities and multiple states were conducted by multiple researchers to gain a better understanding of the array of differences in $\mathrm{MC}$ regulation that can exist between jurisdictions [3, 13-15, 24].

\section{The need for more knowledge, advice, and empirical and clinical evidence to inform future MC policies}

Our analysis showed that many authors called upon the development of future MC policies with a greater degree of supporting evidence through varying means, including: the implementation of empirical and clinical evidence, medical community and physician suggestions, advice from policy officials and experts, and changes to improve patient experiences.

In an effort to include empirical evidence in future MC policies, further research regarding effects of MC reforms proposed included price and tax structures [24], increased cannabis research for re-medicalization [25], and bridging the lack of current political evidence were suggested [20]. Three studies mentioned the reciprocal impacts of MC regulation and clinical research. The classification of MC under the Controlled Substance Act in the US prevents the $\mathrm{MC}$ clinical research required for further legislative actions such as $\mathrm{MC}$ reclassification [26]. Increasing MC clinical research to better understand therapeutic mechanisms and ways to combat drug development lapses could encourage innovation and contribute to MC policy formation [23, 27].

The integration of the medical community into policy decision-making processes and establishing physicians as gatekeepers was proposed by multiple studies [22, 2729]. Due to their medical expertise, prescribing authority, and ability to monitor other FDA-approved drugs [28], it has been recommended that physicians be designated as MC gatekeepers, replacing state governments in this position [29]. It was suggested that physicians' reluctance to involve themselves with $\mathrm{MC}$ leads to decreased safe patient access to MC [22], while their willingness to engage could prevent the spread of misinformation surrounding $M C$ [28] and facilitate its safe and effective use among patients [29]. Accordingly, neglecting the input of these healthcare providers could have negative consequences and should be considered in future MC policies.

A common theme noted between five studies was the implied value of the advice and expertise of policy officials and relevant stakeholders in order to facilitate MC regulation. Strategic planning to establish legitimacy and indications for cannabis use may be facilitated through a multidisciplinary expert committee [25], healthcare professionals [29], medical associations [27], law enforcement $[15,21]$, and patient advocates [21, 29]. 
We found six studies which emphasized revising MC policy implementation processes to improve patient and community experiences. For example, prioritizing patient-centered approaches to care may improve challenges faced by Canadian MC programs [1], while patient protection from prosecution and arrest also has the potential to establish a functional Michigan MC program [17]. In this context, an MC program can be defined as a system for access to MC through a centralized, government-administered plan [1]. Further, a deeper understanding of the effects of governmental institutions on target populations such as retailers and cultivators [21, $30]$, and the incorporation of patient advocates in the implementation of MC policies [20] are both ways in which $\mathrm{MC}$ policies may support the community at-large. In order to facilitate better patient experiences, however, there is a need to address gray areas surrounding the clinical utility of MC for managing diseases and symptoms [27]. In addition, evidence suggests ambiguous MC laws that do not specify a source for MC may implicitly encourage patients to obtain $\mathrm{MC}$ through illegal channels [31]. As such, effective MC laws should provide information about MC sources to reduce the risk of punishment and prioritize patient safety [31].

\section{Discussion}

\section{Significance of findings and comparative literature}

The purpose of the present scoping review is to identify facilitators and barriers to MC regulation. Among the facilitators and barriers we identified, a body of comparative literature exists which supports the present review's findings. One such facilitator includes a given population viewing $\mathrm{MC}$ itself in a positive light. Authors of a qualitative study reported that positive public attitudes about $\mathrm{MC}$ in Israel and Norway were a particularly important factor which supported MC legalization [2]. In addition, evidence demonstrates that countries that allow $\mathrm{MC}$ usage under certain conditions have higher rates of public support for its legalization in comparison to countries that completely forbid the use of MC, identifying a possible reciprocal relationship [32]. A recurring barrier we identified included the need for more clinical and political evidence to inform future MC policies; the National Academies of Sciences, Engineering, and Medicine outlined that further evidence is required for US policymakers to make sound decisions regarding the use of cannabis in their 2017 national report [33]. In addition, Fitzcharles et al. emphasized that there is a need for more sound clinical evidence on the benefits and risks of $\mathrm{MC}$ to inform the advice of physicians and the work of policy regulators [34]. Additionally, researchers reported that individuals in favour of MC supported its legalization as they felt it would become easier to study and allow for a thorough investigation into its therapeutic benefits [32] This complements the findings within our paper which suggest that $\mathrm{MC}$ policies require support from a greater degree of empirical evidence and clinical research in order to facilitate $\mathrm{MC}$ regulation.

The majority of our included articles (16 of 22) discuss MC regulations within the US, thus the themes which emerged from the present review may not be as generalizable to other jurisdictions. Our findings indicate that there is a large base of research focused on the US as the majority of our included articles (16 of 22) discuss MC regulations within the US. There exists several jurisdictions in which MC is legalized, however, we did not find any literature evaluating their MC regulations in a manner consistent with our eligibility criteria. For example, countries including, but not limited to, Austria, Belgium, Croatia, Denmark, and Spain, which have authorized MC use [35], however, we identified no literature evaluating their $\mathrm{MC}$ regulations. As such, it is necessary for future research to investigate $\mathrm{MC}$ regulatory frameworks in other countries in order to obtain a better understanding of facilitators and barriers on a global scale.

\section{Strengths and limitations}

A notable strength of this scoping review included the use of a systematic search strategy to identify a comprehensive pool of synthesized evidence. The interpretation of these findings was strengthened by the use of two assessors who independently partook in the following steps: title/abstract screening, data extraction, and summarization of findings. A limitation of this review includes the fact that we excluded non-English literature which may have resulted in the omission of pertinent research conducted on this topic from countries where English is not a national language/widely-spoken. We did not search the gray literature given that we chose to assess the contents of articles which evaluated MC regulations which are typically found in the peer-reviewed literature.

\section{Conclusion}

The present scoping review involved a systematic search of the literature to identify facilitators and barriers to MC regulation. We provide a comprehensive overview of various factors that influence the MC regulation process while highlighting a number of important themes including: (1) the effects of conflicts, mindset, and ideology of the state population, (2) the use of comparisons to analyze MC regulation, and (3) the need for more knowledge, advice, and empirical/clinical evidence to inform future MC policies. Policymakers should be aware of the facilitators to the $\mathrm{MC}$ regulation implementation process, such as 
the influence of state and federal congruence, increased transparency, and consideration of stakeholder concerns, in order to effectively respond to a growing societal acceptance of $\mathrm{MC}$ and its use among patients. In doing so, these efforts have the potential to overcome barriers to the MC regulation implementation process, including the influence of religiosity and a lack of communication between researchers and policymakers. Through a comprehensive understanding of these influential factors, policymakers will be better equipped to meet the consumer and commercial demands of a rapidly evolving $\mathrm{MC}$ regulatory environment.

\section{Abbreviations}

MC: Medical cannabis; MML: Medical marijuana laws.

\section{Acknowledgements}

JYN was awarded a Research Scholarship and an Entrance Scholarship from the Department of Health Research Methods, Evidence and Impact, Faculty of Health Sciences at McMaster University.

\section{Authors' contributions}

MAR: assisted with the analysis of data, co-drafted the manuscript, and gave final approval of the version to be published. ZG: assisted with the analysis of data, co-drafted the manuscript, and gave final approval of the version to be published. SU: assisted with the collection and analysis of data, critically revised the manuscript, and gave final approval of the version to be published. $\mathrm{PH}$ : assisted with the collection and analysis of data, critically revised the manuscript, and gave final approval of the version to be published. JYN: designed and conceptualized the study, collected and analysed data, critically revised the manuscript, and gave final approval of the version to be published. All authors read and approved the final manuscript.

\section{Funding}

This study was unfunded.

\section{Availability of Data and Materials}

All relevant data are included in this manuscript.

\section{Declarations}

\section{Ethics Approval and Consent to Participate}

This study involved a scoping review of peer-reviewed literature only; it did not require ethics approval or consent to participate.

\section{Consent for Publication}

All authors consent to this manuscript's publication.

\section{Competing Interests}

The authors declare that they have no competing interests.

Received: 22 June 2021 Accepted: 17 September 2021

Published online: 14 October 2021

\section{References}

1. Lucas PG. Regulating compassion: an overview of Canada's federal medical cannabis policy and practice. Harm Reduct J. 2008;5(1):5. https://doi. org/10.1186/1477-7517-5-5.

2. Bridgeman MB, Abazia DT. Medicinal cannabis: history, pharmacology, and implications for the acute care setting. Pharm Ther. 2017:42(3):180-8.

3. Bradford AC, David BW. Factors driving the diffusion of medical marijuana legalisation in the United States. Drugs Educ Prev Policy. 2017;24(1):7584. https://doi.org/10.3109/09687637.2016.1158239.
4. Pacula RL, Smart R. Medical marijuana and marijuana legalization. Annu Rev Clin Psychol. 2017;13:397-419. https://doi.org/10.1146/annurev-clinp sy-032816-045128.

5. Pratt M, Stevens A, Thuku M, Butler C, Skidmore B, Wieland LS, Clemons M, Kanji S, Hutton B. Benefits and harms of medical cannabis: a scoping review of systematic reviews. Syst Rev. 2019;8(1):320. https://doi.org/10. 1186/s13643-019-1243-X.

6. Rehm J, Elton-Marshall T, Sornpaisarn B, Manthey J. Medical marijuana. What can we learn from the experiences in Canada, Germany and Thailand? Int J Drug Policy. 2019;74:47-51. https://doi.org/10.1016/j.drugpo. 2019.09.001.

7. Aguilar S, Gutiérrez V, Sánchez L, Nougier M. Medicinal cannabis policies and practices around the world. Int Drug Policy Consort. Briefing paper. 2018:1-32.

8. Sznitman SR, Bretteville-Jensen AL. Public opinion and medical cannabis policies: examining the role of underlying beliefs and national medical cannabis policies. Harm Reduct J. 2015;12(1):1. https://doi.org/10.1186/ s12954-015-0082-x.

9. Lamonica AK, Boeri M, Anderson T. Gaps in medical marijuana policy implementation: real-time perspectives from marijuana dispensary entrepreneurs, health care professionals and medical marijuana patients. Drugs Educ Prev Policy. 2016;23(5):422-34. https://doi.org/10.3109/09687 637.2016.1150963.

10. Arksey H, O'Malley L. Scoping studies: towards a methodological framework. Int J Soc Res Methodol. 2005;8(1):19-32. https://doi.org/10.1080/ 1364557032000119616.

11. Levac D, Colquhoun H, O'Brien KK. Scoping studies: advancing the methodology. Implement Sci. 2010;5(1):69. https://doi.org/10.1186/ 1748-5908-5-69.

12. Daudt HM, van Mossel C, Scott SJ. Enhancing the scoping study methodology: a large, inter-professional team's experience with Arksey and O'Malley's framework. BMC Med Res Methodol. 2013;13(1):48. https://doi. org/10.1186/1471-2288-13-48.

13. Kim GJ. Policy innovation and diffusion through policy typologies: examining the predictors of Medical Marijuana Legalization in States. http:// purl.flvc.org/fsu/fd/FSU_FA2016_KIM_fsu_0071E_13573.

14. Pacula RL, Boustead AE, Hunt P. Words can be deceiving: a review of variation among legally effective Medical Marijuana Laws in the United States. J Drug Policy Anal. 2014;7(1):1-19. https://doi.org/10.1515/ jdpa-2014-0001.

15. Heddleston T. A tale of three cities: medical marijuana, activism, and local regulation in California. Humboldt J Soc Relat. 2013;35(1):123-43.

16. Tilburg WC, Hodge JG, Gourdet C. Emerging public health law and policy issues concerning state medical cannabis programs. J Law Med Ethics. 2019;47(2_suppl):108-11. https://doi.org/10.1177/1073110519857331.

17. Smith JM. Medical marijuana regulation in Michigan: problems of legitimacy. Deviant Behav. 2013;34(9):751-66. https://doi.org/10.1080/01639 625.2013.766534

18. Choo EK, Emery SL. Clearing the haze: the complexities and challenges of research on state marijuana laws: research on state marijuana laws. Ann N Y Acad Sci. 2017;1394(1):55-73. https://doi.org/10.1111/nyas.13093.

19. Flexon JL, Stolzenberg L, D'Alessio SJ. The effect of cannabis laws on opioid use. Int J Drug Policy. 2019;74:152-9. https://doi.org/10.1016/j. drugpo.2019.09.013.

20. Grbic J, Goddard P, Ryder D. Observations of the role of science in the United States medical cannabis state policies: lessons learnt. Int J Drug Policy. 2017:42:109-14. https://doi.org/10.1016/j.drugpo.2016.12.019.

21. Hammer M. Patients, police, and care providers: the cultural dimension of medical marijuana implementation. Adm Soc. 2015;47(3):282-97. https:// doi.org/10.2139/ssrn.2000705.

22. Lucas P. It can't hurt to ask; a patient-centered quality of service assessment of health Canada's medical cannabis policy and program. Harm Reduct J. 2012;9(1):2. https://doi.org/10.1186/1477-7517-9-2.

23. Miyaji T, Nagasawa M, Yamaguchi T, Tsutani K. Tackling the pharmaceutical frontier: regulation of cannabinoid-based medicines in postwar Japan. Cannabis Cannabinoid Res. 2016;1(1):31-7. https://doi.org/10.1089/can. 2015.0011.

24. Pardo B. Cannabis policy reforms in the Americas: a comparative analysis of Colorado, Washington, and Uruguay. Int J Drug Policy. 2014;25(4):72735. https://doi.org/10.1016/j.drugpo.2014.05.010. 
25. Taylor SL. Evidence-based policy? The re-medicalization of cannabis and the role of expert committees in the UK, 1972-1982. Int J Drug Policy. 2016;37:129-35. https://doi.org/10.1016/j.drugpo.2016.04.014.

26. Campbell AW. The Medical Marijuana Catch-22: how the federal monopoly on marijuana research unfairly handicaps the rescheduling movement. Am J Law Med. 2015;41 (1):190-209. https://doi.org/10.1177/ 0098858815591513

27. Ablin J, Ste-Marie PA, Schäfer M, Häuser W, Fitzcharles M-A. Medical use of cannabis products: lessons to be learned from Israel and Canada. Schmerz. 2016;30(1):3-13. https://doi.org/10.1007/s00482-015-0083-4.

28. Cohen PJ. Medical Marijuana 2010: it's time to fix the regulatory vacuum. J Law Med Ethics. 2010;38(3):654-66. https://doi.org/10.1111/j.1748-720X. 2010.00519.x

29. Zarhin D, Negev M, Vulfsons S, Sznitman SR. Rhetorical and regulatory boundary-work: the case of medical cannabis policy-making in Israel. Soc Sci Med. 2018;217:1-9. https://doi.org/10.1016/j.socscimed.2018.09.047.

30. Davenport S, Pardo B. The Dangerous Drugs Act Amendment in Jamaica: reviewing goals, implementation, and challenges. Int J Drug Policy. 2016;37:60-9. https://doi.org/10.1016/j.drugpo.2016.08.007.

31. Pacula RL, Chriqui JF, Reichmann DA, Terry-McElrath YM. State medical marijuana laws: understanding the laws and their limitations. J Public Health Policy. 2002;23(4):413. https://doi.org/10.2307/3343240.
32. Resko S, Ellis J, Early TJ, Szechy KA, Rodriguez B, Agius E. Understanding public attitudes toward cannabis legalization: qualitative findings from a statewide survey. Subst Use Misuse. 2019;54(8):1247-59. https://doi.org/ 10.1080/10826084.2018.1543327.

33. National Academies of Sciences, Engineering, and Medicine. The health effects of cannabis and cannabinoids: the current state of evidence and recommendations for research. Washington, DC: National Academies Press; 2017. https://doi.org/10.17226/24625.

34. Fitzcharles M-A, Shir Y, Häuser W. Medical cannabis: strengthening evidence in the face of hype and public pressure. CMAJ. 2019;191(33):E907-8.

35. Abuhasira R, Shbiro L, Landschaft Y. Medical use of cannabis and cannabinoids containing products - regulations in Europe and North America. Eur J Intern Med. 2018;49:2-6. https://doi.org/10.1016/j.ejim.2018.01.001.

\section{Publisher's Note}

Springer Nature remains neutral with regard to jurisdictional claims in published maps and institutional affiliations.
Ready to submit your research? Choose BMC and benefit from:

- fast, convenient online submission

- thorough peer review by experienced researchers in your field

- rapid publication on acceptance

- support for research data, including large and complex data types

- gold Open Access which fosters wider collaboration and increased citations

- maximum visibility for your research: over 100M website views per year

At BMC, research is always in progress.

Learn more biomedcentral.com/submissions 